\title{
Electronic couplings and on-site energies for hole transfer in DNA: Systematic quantum mechanical/molecular dynamic study
}

\author{
Alexander A. Voityuk ${ }^{\mathrm{a})}$ \\ Institució Catalana de Recerca i Estudis Avançats, Barcelona 08010, Spain and \\ Institut de Química Computational, Universitat de Girona, 17071 Girona, Spain
}

(Received 14 December 2007; accepted 11 January 2008; published online 17 March 2008)

\begin{abstract}
The electron hole transfer (HT) properties of DNA are substantially affected by thermal fluctuations of the $\pi$ stack structure. Depending on the mutual position of neighboring nucleobases, electronic coupling $V$ may change by several orders of magnitude. In the present paper, we report the results of systematic QM/molecular dynamic (MD) calculations of the electronic couplings and on-site energies for the hole transfer. Based on $15 \mathrm{~ns}$ MD trajectories for several DNA oligomers, we calculate the average coupling squares $\left\langle V^{2}\right\rangle$ and the energies of basepair triplets $X \mathrm{G}^{+} Y$ and $X \mathrm{~A}^{+} Y$, where $X, Y=\mathrm{G}, \mathrm{A}, \mathrm{T}$, and C. For each of the 32 systems, 15000 conformations separated by $1 \mathrm{ps}$ are considered. The three-state generalized Mulliken-Hush method is used to derive electronic couplings for HT between neighboring basepairs. The adiabatic energies and dipole moment matrix elements are computed within the INDO/S method. We compare the rms values of $V$ with the couplings estimated for the idealized $B$-DNA structure and show that in several important cases the couplings calculated for the idealized $B$-DNA structure are considerably underestimated. The rms values for intrastrand couplings G-G, A-A, G-A, and A-G are found to be similar, $\sim 0.07 \mathrm{eV}$, while the interstrand couplings are quite different. The energies of hole states $\mathrm{G}^{+}$and $\mathrm{A}^{+}$in the stack depend on the nature of the neighboring pairs. The $X \mathrm{G}^{+} Y$ are by $0.5 \mathrm{eV}$ more stable than $X \mathrm{~A}^{+} Y$. The thermal fluctuations of the DNA structure facilitate the HT process from guanine to adenine. The tabulated couplings and on-site energies can be used as reference parameters in theoretical and computational studies of HT processes in DNA. () 2008 American Institute of Physics.
\end{abstract}

[DOI: $10.1063 / 1.2841421]$

\section{INTRODUCTION}

During the past decade, charge transfer in DNA has been intensively studied for two reasons: Understanding the mechanisms of the oxidative damage to DNA, and possible applications of DNA-based elements in nanoelectronics, in particular, design and manufacturing biosensor devices. ${ }^{1-4}$ It has recently been shown that the electrical conduction of single molecules, in particular, DNA, is closely related to electron transfer rate, ${ }^{5-7}$ and therefore, computational approaches designed to calculate absolute rates for charge transfer in DNA may be employed to estimate the electrical conductance of single DNA sequences.

The efficiency of charge transport is mainly determined by the electronic coupling $V$ of donor and acceptor sites. The coupling values are usually computed for idealized molecular DNA geometries assuming the validity of the Condon approximation $[V$ does not change with the molecular geometry in the charge transfer (CT) reaction]. Several years ago, it was demonstrated that the electronic coupling for HT between nucleobases in DNA is very sensitive to structural fluctuations and the Condon approximation is rather limited. ${ }^{8}$ Combining molecular dynamics with an approximate scheme for estimating electronic couplings, Troisi and Orlandi showed that in DNA the standard deviation of the coupling of nucleobases is much larger than its average value. ${ }^{9}$ They

${ }^{a)}$ Electronic mail: alexander.voityuk@icrea.es. also concluded that HT in DNA occurs in specific conformations, which may considerably deviate from the canonical $B$-DNA structure. The effects of DNA conformational dynamics on the efficiency of HT have also been considered from different points of view. ${ }^{10-20}$ The obtained results suggest that the electronic couplings found for idealized $B$-DNA (Refs. 21-23) may substantially differ from the corresponding values averaged over thermally accessible DNA configurations, and therefore, a combined quantum mechanical/ molecular dynamic (QM/MD) approach should be used to obtain more accurate estimates of the electronic couplings.

Based on comparison to the CASPT2 and CASSCF results, ${ }^{24}$ it has been demonstrated that the INDO/S method provides surprisingly good estimates for the hole transfer (HT) electronic couplings and energetics in DNA $\pi$ stacks. ${ }^{25}$ In particular, the INDO/S couplings are in better agreement with the reference data than the Hartree-Fock values. Because the INDO/S method is computationally very efficient, one can use this scheme to treat a huge number of structures extracted from MD trajectories. In the present work, we report the results of a systematic QM/MD study of electronic couplings and on-site energies for hole transfer in DNA. For each of the basepair triplets $X \mathrm{G} Y$ and $X \mathrm{~A} Y$, we carry out calculations of 15000 conformations separated by 1 ps. Then, we compare the rms coupling values with the data estimated for the idealized $B$-DNA structure. The tabulated 
TABLE I. 15-mer oligomers used to extract geometries of trimers $X \mathrm{G} Y$ and $X \mathrm{~A} Y$.

\begin{tabular}{|c|c|c|}
\hline Sequence & $X \mathrm{G} Y$ & $X \mathrm{~A} Y$ \\
\hline $\begin{array}{l}5^{\prime}-\mathrm{G} \mathrm{G}(\mathrm{G} \mathrm{G} \mathrm{G} \mathrm{G})_{3} \mathrm{G}-3^{\prime} \\
3^{\prime}-\mathrm{C} \mathrm{C}(\mathrm{C} \mathrm{C} \mathrm{C} \mathrm{C})_{3} \mathrm{C}-3^{\prime}\end{array}$ & GGG & \\
\hline $\begin{array}{l}5^{\prime}-\mathrm{G} \mathrm{A}(\mathrm{G} \mathrm{G} \mathrm{A} \mathrm{A})_{3} \mathrm{G}-3^{\prime} \\
3^{\prime}-\mathrm{C} \text { T }(\mathrm{C} \mathrm{C} \mathrm{T} \mathrm{T})_{3} \mathrm{C}-5^{\prime}\end{array}$ & GGA, AGG & GAA, AAG \\
\hline $\begin{array}{l}5^{\prime}-\mathrm{G} \mathrm{A}(\mathrm{G} \mathrm{A} \mathrm{G} \mathrm{A})_{3} \mathrm{G}-3^{\prime} \\
3^{\prime}-\mathrm{C} \text { T }(\mathrm{C} \mathrm{T} \mathrm{C} \mathrm{T})_{3} \mathrm{C}-5^{\prime}\end{array}$ & AGA & GAG, \\
\hline $\begin{array}{l}5^{\prime}-\mathrm{G} \mathrm{A}(\mathrm{A} \mathrm{A} \mathrm{A} \mathrm{A})_{3} \mathrm{G}-3^{\prime} \\
3^{\prime}-\mathrm{C} \text { T }(\text { T T T T })_{3} \mathrm{C}-5^{\prime}\end{array}$ & & AAA \\
\hline $\begin{array}{l}5^{\prime}-\mathrm{G} \mathrm{T}(\mathrm{G} \mathrm{G} \mathrm{T} \mathrm{T})_{3} \mathrm{G}-3^{\prime} \\
3^{\prime}-\mathrm{C} \mathrm{A}(\mathrm{C} \mathrm{C} \mathrm{A} \mathrm{A})_{3} \mathrm{C}-5^{\prime}\end{array}$ & GGT, TGG & \\
\hline $\begin{array}{l}5^{\prime}-\mathrm{G} \mathrm{C}(\mathrm{G} \mathrm{G} \mathrm{C} \mathrm{C})_{3} \mathrm{G}-3^{\prime} \\
3^{\prime}-\mathrm{C} \mathrm{G}(\mathrm{C} \mathrm{C} \mathrm{G} \mathrm{G})_{3} \mathrm{C}-5^{\prime}\end{array}$ & GGC, CGG & \\
\hline $\begin{array}{l}5^{\prime}-\mathrm{G} \mathrm{C}\left(\mathrm{A} \mathrm{A} \mathrm{A} \mathrm{C}_{3} \mathrm{G}-3^{\prime}\right. \\
3^{\prime}-\mathrm{C} \mathrm{G}\left(\mathrm{T} \mathrm{T} \mathrm{T} \mathrm{G}_{3} \mathrm{C}-5^{\prime}\right.\end{array}$ & & $\mathrm{AAC}, \mathrm{CAA}$ \\
\hline $\begin{array}{l}5^{\prime}-\mathrm{G} \mathrm{T}(\mathrm{G} \mathrm{A} \mathrm{C} \mathrm{T})_{3} \mathrm{G}-3^{\prime} \\
3^{\prime}-\mathrm{C} \mathrm{A}(\mathrm{C} \mathrm{T} \mathrm{G} \mathrm{A})_{3} \mathrm{C}-5^{\prime}\end{array}$ & AGT, TGA & GAC, CAG \\
\hline $\begin{array}{l}5^{\prime}-\mathrm{G} \mathrm{C}(\mathrm{G} \mathrm{A} \mathrm{G} \mathrm{C})_{3} \mathrm{G}-3^{\prime} \\
3^{\prime}-\mathrm{C} \mathrm{G}(\mathrm{C} \mathrm{T} \mathrm{C} \mathrm{G})_{3} \mathrm{C}-5^{\prime}\end{array}$ & AGC, CGA & \\
\hline $\begin{array}{l}5^{\prime}-\mathrm{G} \mathrm{T}(\mathrm{G} \mathrm{C} \mathrm{G} \mathrm{T})_{3} \mathrm{G}-3^{\prime} \\
3^{\prime}-\mathrm{C} \mathrm{A}(\mathrm{C} \mathrm{G} \mathrm{C} \mathrm{A})_{3} \mathrm{C}-5^{\prime}\end{array}$ & TGC, CGT & \\
\hline $\begin{array}{l}5^{\prime}-\mathrm{G} \mathrm{T}(\mathrm{G} \mathrm{T} \mathrm{G} \mathrm{T})_{3} \mathrm{G}-3^{\prime} \\
3^{\prime}-\mathrm{C} \mathrm{A}(\mathrm{C} \mathrm{A} \mathrm{C} \mathrm{A})_{3} \mathrm{C}-5^{\prime}\end{array}$ & TGT & CAC \\
\hline $\begin{array}{l}5^{\prime}-\mathrm{G} \mathrm{C}(\mathrm{G} \mathrm{C} \mathrm{G} \mathrm{C})_{3} \mathrm{G}-3^{\prime} \\
3^{\prime}-\mathrm{C} \mathrm{G}(\mathrm{C} \mathrm{G} \mathrm{C} \mathrm{G})_{3} \mathrm{C}-5^{\prime}\end{array}$ & CGC & \\
\hline $\begin{array}{l}5^{\prime}-\mathrm{G} \text { T }(\text { ( А А T T })_{3} \mathrm{G}-3^{\prime} \\
3^{\prime}-\mathrm{C} \text { А }(\text { ( Т Т А А })_{3} \mathrm{C}-5^{\prime}\end{array}$ & & AAT, TAA \\
\hline $\begin{array}{l}5^{\prime}-\mathrm{G} \mathrm{T}(\mathrm{A} \mathrm{C} \mathrm{A} \mathrm{T})_{3} \mathrm{G}-3^{\prime} \\
3^{\prime}-\mathrm{C} \mathrm{A}(\mathrm{T} \mathrm{G} \mathrm{T} \mathrm{A})_{3} \mathrm{C}-5^{\prime}\end{array}$ & & CAT \\
\hline 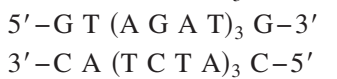 & & GAT, TAG \\
\hline $\begin{array}{l}5^{\prime}-\mathrm{G} \mathrm{C}(\mathrm{G} \mathrm{T} \mathrm{A} \mathrm{C})_{3} \mathrm{G}-3^{\prime} \\
3^{\prime}-\mathrm{C} \mathrm{G}(\mathrm{C} \mathrm{A} \mathrm{T} \mathrm{G})_{3} \mathrm{C}-5^{\prime}\end{array}$ & & TAC \\
\hline $\begin{array}{l}5^{\prime}-\mathrm{G} \mathrm{T}(\mathrm{A} \mathrm{T} \mathrm{A} \mathrm{T})_{3} \mathrm{G}-3^{\prime} \\
3^{\prime}-\mathrm{C} \text { А }(\text { ( } \mathrm{A} \mathrm{A} \mathrm{T} \mathrm{A})_{3} \mathrm{C}-5^{\prime}\end{array}$ & & TAT \\
\hline
\end{tabular}

QM/MD couplings and on-site energies may be used as reference parameters in theoretical and computational studies of hole transfer phenomena in DNA.

\section{COMPUTATIONAL DETAILS}

Our quantum mechanical calculations are based on the $15 \mathrm{~ns}$ benchmark MD trajectories for several doublestranded DNA sequences (Table I) obtained within ABC project. $^{26}$ The trajectory and parameter files were downloaded from the website of the Beveridge group. ${ }^{27}$ Each of considered 15-basepair oligomers contains three tetranucleotide repeats $5^{\prime}-\mathrm{G} \mathrm{D}(\mathrm{A} B \mathrm{C} \mathrm{D})_{3}$ G-3'. The basepair triplets $X \mathrm{G} Y$ and $X \mathrm{~A} Y$ were extracted from the sequences as listed in Table I. To avoid potential artifacts from end effects, the triplets were taken from a middle part of the oligomers (the considered triplets are placed at least five basepairs from the ends of oligomers).

$M D$ simulations. It was performed by $\mathrm{ABC}$ consortium ${ }^{26}$ using well established protocol $(T=300 \mathrm{~K}, P=1 \mathrm{~atm}, 2 \mathrm{fs}$ integration step, parm94 force field, ${ }^{28}$ TIP3P water molecules, ${ }^{29}$ periodic boundary conditions, cutoff of $9 \AA$ for nonbonded interactions, particle-mesh Ewald algorithm ${ }^{30}$ for treatment of electrostatic interactions). Details of the simulation protocol are described in Ref. 26.

Quantum chemical calculations. As noted above, the INDO/S (Ref. 31) method provides accurate values of electronic coupling and on-site energies. ${ }^{25}$ The scheme is computationally very efficient; it allows us to treat all 1 ps snapshots for $X \mathrm{G} Y$ and $X \mathrm{~A} Y$ triplets extracted from $15 \mathrm{~ns} \mathrm{MD}$ trajectories (15 000 different conformations were calculated for each of the 32 basepair triplets). The adiabatic energies and dipole moment matrix elements were computed with the INDO/S approach. We used the generalized Mulliken-Hush $(\mathrm{GMH})$ method introduced by Cave and Newton ${ }^{32,33}$ to derive electronic couplings and on-site energies. Within this scheme the diabatic states are chosen diagonal with respect to the component of the dipole moment operator along the main DNA axis. Once the unitary transformation $T$ is defined, the electronic couplings (off-diagonal matrix elements of the diabatic Hamiltonian) can be calculated as $V_{d a}$ $=\sum T_{i d} E_{i} T_{i a}$. The three-state formulation of the method was applied (details of calculations are considered elsewhere, Ref. 20). The use of the three-state GMH scheme for triplet $X \mathrm{~B} Y$ makes it possible to obtain at once the electronic couplings $V(X-B), V(B-Y)$, and $V(X-Y)$ as well as the on-site energies $E\left(X^{+}\right), E\left(B^{+}\right)$, and $E\left(Y^{+}\right)$(diagonal elements of the diabatic Hamiltonian) corresponding to the states with the hole on basepairs $X, B$, and $Y$, respectively. Because the onsite energies are sensitive to the nature of neighboring basepairs, ${ }^{34}$ below we consider the dependence of the $B^{+}$ state energies on the nature of $X$ and $Y$ neighbors.

\section{RESULTS AND DISCUSSION}

\section{Electronic couplings}

As a measure of the coupling we use its root mean square $V_{\mathrm{rms}}, V_{\mathrm{rms}}=\sqrt{\left\langle V^{2}\right\rangle}=\sqrt{(1 / n) \sum_{i=1}^{n} V_{i}^{2}}$, where $\langle\cdots\rangle$ denotes the arithmetic mean, the sum is taken over $n$ configurations. By definition, $V_{\mathrm{rms}}^{2}=\langle V\rangle^{2}+\sigma^{2}$, where $\sigma$ is the standard deviation of $V$. The use of $V_{\text {rms }}$ rather than $\langle V\rangle$ is in line with the expression for the nonadiabatic CT. ${ }^{35,36}$ For structurally flexible donor-acceptor systems the rate constant can be expressed as $k=2 / \hbar V_{\mathrm{rms}}^{2} \rho_{\mathrm{FC}}$, if fluctuations in the coupling are slower than the evolution of the Franck-Condon factor $\rho_{\mathrm{FC}}{ }^{37}$

The intra- and interstrand couplings derived for different 32 basepair triplets are listed in Tables II and III.

Intrastrand couplings. Each of the intrastrand couplings $V(\mathrm{G}-\mathrm{G}), V(\mathrm{~A}-\mathrm{A}), V(\mathrm{G}-\mathrm{A})$, and $V(\mathrm{~A}-\mathrm{G})$ was extracted from the calculation of several triplets (Table II). Let us consider, for instance, the $V(\mathrm{G}-\mathrm{G})$ values. In the oligomer $5^{\prime}-\mathrm{GG}$ $(\mathrm{GGGG})_{3}$ G-3', the G-G couplings are expected to be (almost) identical. However, the calculation of $\mathrm{G}_{7} \mathrm{G}_{8} \mathrm{G}_{9}$ (indices $i, j$, and $k$ in triplet $X_{i} B_{j} Y_{k}$ point at the basepair position in oligomers) gives $V\left(\mathrm{G}_{7}-\mathrm{G}_{8}\right)$ and $V\left(\mathrm{G}_{8}-\mathrm{G}_{9}\right)$ to be $0.0707 \mathrm{eV}$ and $0.0627 \mathrm{eV}$, respectively. The difference (by $\sim 10 \%$ ) encountered in the calculation is due to the fact that $G_{7}$ and $G_{9}$ are nonequivalent even in the ideal $B$-DNA stacks because of the helical structure (they become equivalent in a completely unwound triplet structure). From calculations of the triplet $\mathrm{G}_{8} \mathrm{G}_{9} \mathrm{G}_{10}$ we get $V\left(\mathrm{G}_{8}-\mathrm{G}_{9}\right)=0.0701 \mathrm{eV}$ and $V\left(\mathrm{G}_{9}-\mathrm{G}_{10}\right)$ 
TABLE II. Intrastrand couplings $V_{\text {rms }}$ of neighboring pairs, (eV) derived for different triplets. (The calculated triplets are in parentheses. The bold $\mathrm{G}$ and A mark the basepairs for which the coupling is computed.)

\begin{tabular}{|c|c|c|c|c|}
\hline & G-G & $\mathbf{A}-\mathbf{A}$ & G-A & A-G \\
\hline & $0.0707(\mathbf{G G G})$ & $0.0582(\mathbf{A A G})$ & $0.0580(\mathbf{G A G})$ & $0.0619(\mathbf{A G G})$ \\
\hline & 0.0746 (GGA) & $0.0532(\mathbf{A A A})$ & $0.0446($ GAA $)$ & 0.0841 (AGA) \\
\hline & $0.0950(\mathbf{G G T})$ & $0.0634(\mathbf{A A T})$ & $0.0656(\mathbf{G A T})$ & $0.0783(\mathbf{A G T})$ \\
\hline & 0.0871 (GGC) & $0.0724(\mathbf{A A C})$ & $0.0833($ GAC $)$ & $0.0714($ AGC $)$ \\
\hline & 0.0627 (GGG) & $0.0624(\mathrm{GAA})$ & 0.0746 (GGA) & 0.0671 (GAG) \\
\hline & 0.0753 (AGG) & $0.0576(\mathrm{AAA})$ & 0.0616 (AGA) & 0.0696 (AAG) \\
\hline & 0.0954 (TGG) & 0.0647 (TAA) & 0.0851 (TGA) & $0.0680(\mathrm{TAG})$ \\
\hline & 0.0852 (CGG) & $0.0724(\mathbf{C A A})$ & 0.0815 (CGA) & 0.0798 (CAG) \\
\hline Av. & 0.0804 & 0.0630 & 0.0692 & 0.0725 \\
\hline
\end{tabular}

$=0.0648 \mathrm{eV}$ which are very close to $V\left(\mathrm{G}_{7}-\mathrm{G}_{8}\right)$ and $V\left(\mathrm{G}_{8}-\mathrm{G}_{9}\right)$ found in $\mathrm{G}_{7} \mathrm{G}_{8} \mathrm{G}_{9}$. It means that the difference of $\mathrm{G}-\mathrm{G}$ couplings in the GGG triplets is solely caused by the end effects. In principle, these effects can be reduced by treating more extended QM models consisting, for instance, of four or five basepairs. However, such an approach will not only result in considerable computational cost but may also lead to serious difficulties by estimating the couplings using the multistate GMH scheme. As recommended by Cave and Newton, the number of states $n$ treated simultaneously should be kept as small as possible. ${ }^{32}$ Taking into account that many thousands of calculations must be performed, a consistent multistate analysis with $n>3$ is rather difficult.

Comparison of $V(\mathrm{G}-\mathrm{G})$ values extracted from the calculation of GGY and XGG (Table II) suggests that the coupling depends on the nature of neighboring pairs $X$ and $Y$. The coupling increases when $X$ or $Y$ changes as follows $\mathrm{G}<\mathrm{A}$ $<\mathrm{C}<\mathrm{T}$. This effect may be associated with the two factors. First, alteration of neighboring pair leads to slightly different conformations of the G-G basepair step. However, this factor appears to be rather small. ${ }^{26}$ Second, the energy of hole state $X \mathrm{G}^{+} \mathrm{G}$ and $\mathrm{GG}^{+} Y$ becomes higher when purine nucleobases $(\mathrm{G}$ and $\mathrm{A})$ are replaced by pyrimidine nucleobases $(\mathrm{C}$ and $\mathrm{T})$.

Similar behavior is also found for $V(\mathrm{~A}-\mathrm{A}), V(\mathrm{G}-\mathrm{A})$, and $V(\mathrm{~A}-\mathrm{G})$ (Table II). In particular, the $V_{\text {rms }}$ value of A-A coupling ranges from 0.05 to $0.07 \mathrm{eV}$ (Table II); in AAY and $\mathrm{XAA}$ the coupling increases by variation of $X$ and $Y$ in the following manner $\mathrm{A}<\mathrm{G}<\mathrm{C}<\mathrm{T}$.

Overall, $V_{\text {rms }}$ values for G-G, A-A, G-A, and A-G are

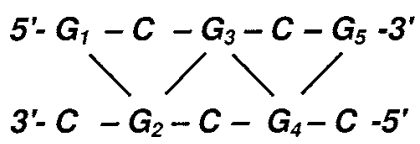

SCHEME 1. Interstrand HT in poly-(GC) sequences.

found to be similar and the average value of $0.07 \mathrm{eV}$ can be used to describe the intrastrand coupling of purine nucleobases in DNA $\pi$-stack.

Interstrand couplings. In poly-(GC) double-strand sequence the hole transfer rate depends on the interstrand couplings of guanines (see Scheme 1).

Even in the ideal $\pi$-stack, the mutual position of $\mathrm{G}_{1}-\mathrm{G}_{2}$ and $\mathrm{G}_{2}-\mathrm{G}_{3}$ are quite different. The structural dissimilarity of $\mathrm{G}_{1} \mathrm{G}_{2}$ and $\mathrm{G}_{2} \mathrm{G}_{3}$ stacks is reflected in the coupling values $\mathrm{G} \backslash \mathrm{G}$ and $\mathrm{G} / \mathrm{G}$, respectively (hereafter to designate the mutual position of the nucleotides in opposite strands we use $B \backslash B^{\prime}$ for the configuration like $\mathrm{G}_{1} \mathrm{G}_{2}$ or $\mathrm{G}_{3} \mathrm{G}_{4}$, and $B / B^{\prime}$ for the position $\mathrm{G}_{3} \mathrm{G}_{2}$ or $\mathrm{G}_{5} \mathrm{G}_{4}$, see Scheme 1). Our calculations of $V_{\text {rms }}$ for $\mathrm{G} / \mathrm{G}$ and $\mathrm{GlG}$ show that these couplings are quite different (by a factor of 4); the average values of $V(\mathrm{G} / \mathrm{G})$ and $V(\mathrm{G} \backslash \mathrm{G})$ are found to be 0.0076 and $0.031 \mathrm{eV}$ (Table III).

Also, for other combinations of nucleobases (Table III), the coupling of $B / B^{\prime}$ is considerably stronger than that of $B \backslash B^{\prime}$. For $\mathrm{A} / \mathrm{A}$ and $\mathrm{A} \backslash \mathrm{A}$, the average $V_{\text {rms }}$ values $(0.064$ and $0.017 \mathrm{eV}$, respectively) differ by a factor of 4, while $V(\mathrm{G} / \mathrm{A})=0.037 \mathrm{eV}$ is three times stronger than $V(\mathrm{G} \backslash \mathrm{A})$ $=0.012 \mathrm{eV}$. Note that configurations G/A and A/G (as well as G\A and $A \backslash G)$ are equivalent. Because of a significant difference of $V\left(B \backslash B^{\prime}\right)$ and $V\left(B / B^{\prime}\right)$, the efficiency of hole transfer through a DNA stack with alternating purine-pyrimidine nucleobases will be determined by the product of the corresponding couplings; for instance, in poly(GT)-poly(AC), the effective coupling squared is equal to $|V(G \backslash A) \cdot V(G / A)|$.

\section{Comparison to ideal $B$-DNA}

As noted in the Introduction, the theoretical analysis of hole transport in DNA is usually based on the couplings derived for ideal $B$-DNA. ${ }^{21-23}$ In Table IV, we compare the values derived from the QM/MD computations with the couplings calculated for the idealized $\pi$-stack geometries. As can be seen, in several cases the couplings calculated for ideal $B$-DNA structure significantly differ from the QM/MD data. More specifically, the intrastrand G-A and A-G cou-

TABLE III. QM/MD interstrand couplings of neighboring pairs $(\mathrm{eV})$ derived for different triplets. The calculated triplets are in parentheses. The bold G and A mark the basepairs for which the coupling is computed.

\begin{tabular}{cccccc}
\hline \hline \multicolumn{1}{c}{$\mathbf{G} / \mathbf{G}$} & $\mathbf{G} \backslash \mathbf{G}$ & $\mathbf{A} / \mathbf{A}$ & $\mathbf{A} \backslash \mathbf{A}$ & $\mathbf{G} / \mathbf{A}, \mathbf{A} / \mathbf{G}$ & $\mathbf{G} \backslash \mathbf{A}, \mathbf{A} \backslash \mathbf{G}$ \\
\hline $0.0303(\mathbf{C G G})$ & $0.0092(\mathrm{GGC})$ & $0.0736(\mathrm{TAG})$ & $0.0175(\mathrm{GAT})$ & $0.0378(\mathrm{CAG})$ & $0.0097(\mathrm{GGT})$ \\
$0.0260(\mathbf{C G A})$ & $0.0078(\mathrm{AGC})$ & $0.0680(\mathrm{TAA})$ & $0.0183(\mathrm{AAT})$ & $0.0432(\mathrm{CAA})$ & $0.0114(\mathrm{AGT})$ \\
$0.0398(\mathbf{C G T})$ & $0.0049(\mathrm{TGC})$ & $0.0649(\mathrm{TAT})$ & $0.0155(\mathrm{TAT})$ & $0.0372(\mathrm{CAC})$ & $0.0122(\mathrm{TGT})$ \\
$0.0298(\mathbf{C G C})$ & $0.0083(\mathrm{CGC})$ & $0.0507(\mathrm{TAC})$ & $0.0172(\mathrm{CAT})$ & $0.0346(\mathrm{CAT})$ & $0.0120(\mathrm{CGT})$ \\
& & & & $0.0388(\mathrm{TGG})$ & $0.0122(\mathrm{GAC})$ \\
& & & & $0.0404(\mathrm{TGA})$ & $0.0101(\mathrm{AAC})$ \\
& & & & $0.0360(\mathrm{TGT})$ & $0.0126(\mathrm{TAC})$ \\
& & & 0.017 & 0.037 & 0.012 \\
Av. 0.031 & 0.0076 & 0.064 & & & \\
\hline \hline
\end{tabular}


TABLE IV. Comparison of the QM/MD couplings, with estimates derived for ideal $B$-DNA.

\begin{tabular}{lllll}
\hline \hline & & \multicolumn{3}{c}{ Idealized structure } \\
\cline { 3 - 5 } Intrastrand coupling & QM/MD & INDO/S & HF $^{\mathrm{a}}$ & $\mathrm{DFT}^{\mathrm{b}}$ \\
\hline G-G & $\mathbf{0 . 0 8 0 4}$ & 0.037 & 0.084 & 0.053 \\
A-A & $\mathbf{0 . 0 6 3 0}$ & 0.024 & 0.030 & 0.004 \\
G-A & $\mathbf{0 . 0 6 9 2}$ & 0.066 & 0.089 & 0.077 \\
A-G & $\mathbf{0 . 0 7 2 5}$ & 0.052 & 0.049 & 0.010 \\
Interstrand coupling & & & & \\
G/G & $\mathbf{0 . 0 3 1 5}$ & 0.019 & 0.043 & 0.032 \\
GlG & $\mathbf{0 . 0 0 7 6}$ & 0.013 & 0.019 & 0.012 \\
A/A & $\mathbf{0 . 0 6 4 3}$ & 0.046 & 0.062 & 0.049 \\
AlA & $\mathbf{0 . 0 1 7 1}$ & 0.020 & 0.034 & 0.031 \\
G/A, A/G & $\mathbf{0 . 0 3 6 8}$ & 0.009 & 0.004 & 0.011 \\
G\A, AlG & $\mathbf{0 . 0 1 1 7}$ & 0.007 & 0.021 & 0.013 \\
\hline \hline
\end{tabular}

${ }^{\mathrm{a}}$ Reference 22 .

${ }^{\mathrm{b}}$ Unsigned values are given (Ref. 23).

plings as well as the interstrand $\mathrm{G} / \mathrm{G}$ and $\mathrm{A} / \mathrm{A}$ couplings in the basepair stacks of the ideal structures are in reasonable agreement with the QM/MD results; however, in all other cases the couplings derived for ideal $B$-DNA do not agree with the $V_{\mathrm{rms}}$ values. Especially large deviations are found for $V(\mathrm{~A}-\mathrm{A})$, and $V(\mathrm{G} / \mathrm{A})$.

As already noted, HT couplings are extremely sensitive to conformational fluctuations. As an example, let us consider the data for coupling in the AAG trimer. As illustrated in Fig. 1, the coupling oscillates around zero frequently changing the sign. Its mean value of $\sim-0.015 \mathrm{eV}$ is by a factor of 4 smaller than the standard deviation $\sigma=0.058 \mathrm{eV}$. Thus, the magnitude of $V_{\mathrm{rms}}(\mathrm{A}-\mathrm{A})$, which is very close to the $\sigma$, is almost completely determined by structural fluctuations. Such a situation is also observed for other couplings. Taking into account the extreme sensitivity of $V$ to conformational changes, the acceptable estimates obtained for the idealized $B$-DNA structure appear to be really surprising. Based on that data many important results on the HT properties of different DNA sequences have been derived. ${ }^{10,21-23,38,39}$

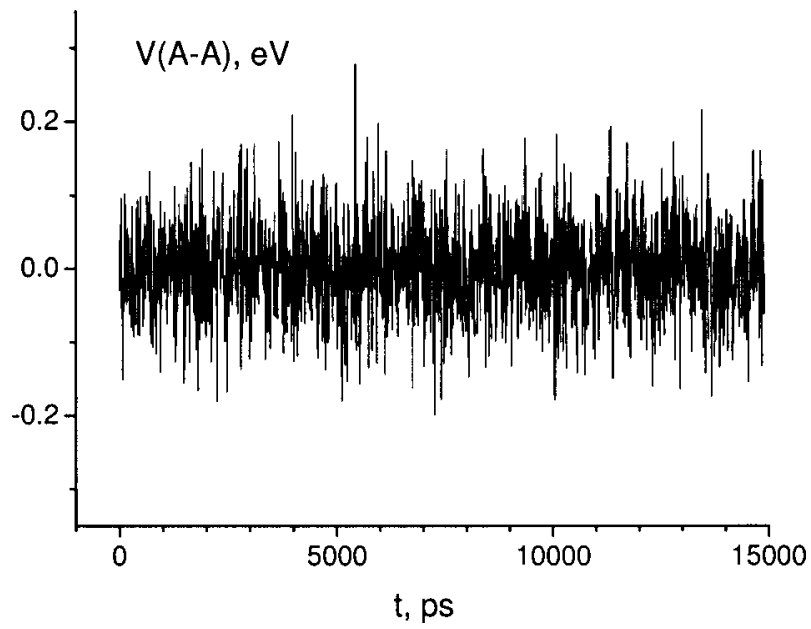

FIG. 1. Fluctuations of electronic coupling A-A calculated in the basepair trimer AAG.
TABLE V. On-site energies for hole states $X B^{+} Y$ localized on $\mathrm{G}$ and $\mathrm{A}(\mathrm{eV})$.

\begin{tabular}{lll}
\hline \hline$X B Y$ & $E\left(\mathrm{G}^{+}\right)$ & $E\left(\mathrm{~A}^{+}\right)$ \\
\hline GBG & 6.538 & 7.068 \\
GBA & 6.673 & 7.117 \\
GBT & 6.818 & 7.358 \\
GBC & 6.841 & 7.388 \\
ABG & 6.518 & 7.018 \\
ABA & 6.614 & 7.161 \\
ABT & 6.817 & 7.329 \\
ABC & 6.811 & 7.369 \\
TBG & 6.644 & 7.148 \\
TBA & 6.701 & 7.244 \\
TBT & 6.841 & 7.416 \\
TBC & 6.888 & 7.384 \\
CBG & 6.634 & 7.229 \\
CBA & 6.723 & 7.308 \\
CBT & 6.907 & 7.481 \\
CGC & 6.919 & 7.494 \\
\hline
\end{tabular}

\section{On-site energies}

The energetics of hole states was already studied for DNA $\pi$-stacks of the ideal geometry. ${ }^{34,40}$ It was shown that the energetic stabilization of a hole state $B^{+}$in $5^{\prime}-X B Y-3^{\prime}$ duplexes is considerably influenced by the subsequent base $Y$ while the effect of the preceding base $X$ is rather small. ${ }^{34}$ Unlike electronic couplings, the energies of $\mathrm{G}^{+}$and $\mathrm{A}^{+}$hole states are found to be not very responsive to conformational fluctuations. Table $\mathrm{V}$ lists the mean values of on-site energies for hole states $\mathrm{G}^{+}$and $\mathrm{A}^{+}$in the triplets calculated for $15 \mathrm{~ns}$ trajectories for DNA oligomers (Table I). As expected, the most effective trap for cation radical states is guanine in triplets GGG and AGG. Replacing $5^{\prime}-X$ by $\mathrm{T}$ or $\mathrm{C}$ leads to destabilization of $X \mathrm{G}^{+} \mathrm{G}$ by $0.1 \mathrm{eV}$. As noted above, the $Y-3^{\prime}$ nucleotide has an essentially larger effect on the $\mathrm{G}^{+}$energetics. As compared to $5^{\prime}-X \mathrm{G}^{+} \mathrm{G}-3^{\prime}$, the $\mathrm{G}^{+}$state in $5^{\prime}-X \mathrm{G}^{+} \mathrm{A}-3^{\prime}$ are less stable by about $\sim 0.10 \mathrm{eV}$ (Table $\mathrm{V}$ ), followed by $5^{\prime}-X \mathrm{G}^{+} \mathrm{T}-3^{\prime} \quad(0.27 \mathrm{eV})$ and $5^{\prime}-X \mathrm{G}^{+} \mathrm{C}-3^{\prime}$ $(0.30 \mathrm{eV})$. Thus, the stabilizing effect of $3^{\prime}-Y$ neighbors decreases in the order $\mathrm{G}>\mathrm{A}>\mathrm{T} \geqslant \mathrm{C}$.

The calculated energies of $\mathrm{XA}^{+} Y$ states are also listed in Table $\mathrm{V}$. The mean difference between ionization energies of $A$ and $G$ in the triplets with identical neighbors is about $0.5 \mathrm{eV}$. The smallest difference of $0.34 \mathrm{eV}$ is found for $\mathrm{GA}^{+} \mathrm{A}$ and $\mathrm{GG}^{+} \mathrm{A}$. There is no overlap between the ionization potential of $\mathrm{G}$ and $\mathrm{A}$, independent of neighboring nucleotides in $X \mathrm{G}^{+} Y$; the $G^{+}$states of the highest energy (e.g., in $\mathrm{CG}^{+} \mathrm{C}$ ) are found to be more stable by $0.1 \mathrm{eV}$ than the lowest-energy states $\mathrm{AA}^{+} \mathrm{G}$ and $\mathrm{GA}^{+} \mathrm{G}$ (see Table V).

The $\mathrm{QM} / \mathrm{MD}$ calculations show that the main results on the energetics of $\mathrm{G}^{+}$and $\mathrm{A}^{+}$hole states in DNA, previously established for ideal $\pi$-stacks, ${ }^{34}$ do not change significantly. However, structural fluctuations of the $\pi$-stack lead to qualitatively new picture, facilitating the thermal hole transfer $\mathrm{G}^{+} \rightarrow \mathrm{A}^{+}$within DNA. The thermal fluctuations cause variations of the diabatic energies of $\mathrm{G}^{+}$and $\mathrm{A}^{+}$. The corresponding standard deviations are almost independent of the neighboring basepairs and found to be of $\sim 0.15 \mathrm{eV}$. If one takes into account also environmental fluctuations (movement of 
water molecules and counterions), ${ }^{15} \sigma$ becomes about $0.22 \mathrm{eV}$. Then, the standard deviation of the free energy $\Delta \mathrm{G}$ for hole transfer $\mathrm{G}^{+} \rightarrow \mathrm{A}^{+}$can be estimated as $\sigma^{2}$ $\approx \sigma^{2}\left(E\left(\mathrm{G}^{+}\right)\right)+\sigma^{2}\left(E\left(\mathrm{~A}^{+}\right)\right) \approx 2 \times 0.22^{2} \approx 0.1 \mathrm{eV},{ }^{2}$ leading to $\sigma(\Delta \mathrm{G}) \approx 0.3 \mathrm{eV}$. Because the estimated value of $\sigma(\Delta \mathrm{G})$ is comparable to the energy gap $E\left(\mathrm{~A}^{+}\right)-E\left(\mathrm{G}^{+}\right)$of $\sim 0.5 \mathrm{eV}$, the thermally induced $\mathrm{G}^{+} \rightarrow \mathrm{A}^{+}$hole transfer in DNA appears to be quite possible.

\section{CONCLUSIONS}

In many theoretical studies on hole transport in DNA, the electronic couplings have been used which were derived for basepair stacks of idealized structure. However, these parameters are known to be very sensitive to conformational changes in the $\pi$ stack. To justify this situation, we carried out the systematic study of electronic coupling for hole transfer between nucleobases in DNA using a QM/MD approach. Based on $15 \mathrm{~ns}$ MD trajectories for several DNA oligomers, we calculate average coupling squares $\left\langle V^{2}\right\rangle$ and mean on-site energies in the basepair triplets $X \mathrm{G} Y$ and $X \mathrm{~A} Y$, where $X, \mathrm{Y}$ $=\mathrm{G}, \mathrm{A}, \mathrm{T}$, and $\mathrm{C}$.

We found that in several important cases the couplings estimated for the idealized $B$-DNA structure differ considerably from the $\mathrm{QM} / \mathrm{MD}$ results, especially large deviations are found for the $V(\mathrm{~A}-\mathrm{A})$ and $V(\mathrm{G} / \mathrm{A})$. Because those couplings are much smaller than the corresponding $\mathrm{QM} / \mathrm{MD}$ values, the HT efficiency calculated ignoring thermal fluctuations can be underestimated by several orders of magnitude.

Unlike electronic couplings, the energies of the hole states $\mathrm{G}^{+}$and $\mathrm{A}^{+}$are not very sensitive to conformational changes. The effects of neighboring nucleobases on the HT energetics and numerical estimates, which were established for ideal $\pi$-stacks, remain almost unchanged. While the states $X \mathrm{G}^{+} Y$ are found by $0.5 \mathrm{eV}$ more stable than the $X \mathrm{~A}^{+} Y$ states, structural fluctuations of DNA allow the hole to be transferred from $\mathrm{G}$ to $\mathrm{A}$.

The tabulated QM/MD results for the electronic couplings and on-site energies can be used as reference parameters in theoretical and computational studies of electrical conductance and other phenomena related to hole transport through DNA.

\section{ACKNOWLEDGMENTS}

This work has been supported by the Spanish Ministerio de Educación y Ciencia, Project No. CTQ2005-04563.

\footnotetext{
${ }^{1}$ Long-Range Electron Transfer in DNA, Topics in Current Chemistry Vols. 236 and 237, edited by G. B. Schuster (Springer, Berlin, 2004).

${ }^{2}$ Charge Transfer in DNA, edited by H.-A. Wagenknecht (Wiley-VCH, Weinheim, 2005).
}

${ }^{3}$ R. G. Endres, D. L. Cox, and P. R. P. Singh, Rev. Mod. Phys. 76, 195 (2004).

${ }^{4}$ E. Macia, Phys. Rev. B 75, 035130 (2007).

${ }_{6}^{5}$ A. Nitzan, J. Phys. Chem. A 105, 2677 (2001).

${ }^{6}$ A. Nitzan and M. A. Ratner, Science 300, 1384 (2003).

${ }^{7}$ Y. A. Berlin and M. A. Ratner, Radiat. Phys. Chem. 74, 124 (2005).

${ }^{8}$ A. A. Voityuk, K. Siriwong, and N. Rösch, Phys. Chem. Chem. Phys. 3, 5421 (2001).

${ }^{9}$ A. Troisi and G. Orlandi, J. Phys. Chem. B 106, 2093 (2002).

${ }^{10}$ Y. A. Berlin, I. V. Kurnikov, D. N. Bertran, M. A. Ratner, and A. L. Burin, Top. Curr. Chem. 237, 1 (2004).

${ }^{11}$ F. C. Grozema, L. D. A. Siebbeles, Y. A. Berlin, and M. A. Ratner, ChemPhysChem 3, 536 (2002).

${ }^{12}$ E. Macia, Phys. Rev. B 76, 245123 (2007).

${ }^{13}$ J. P. Lewis, T. E. Cheatham, E. B. Starikov, H. Wang, and O. F. Sankey, J. Phys. Chem. B 107, 2581 (2003).

${ }^{14}$ T. Cramer, T. Steinbrecher, A. Labahn, and T. Koslowski, Phys. Chem. Chem. Phys. 7, 4039 (2005).

${ }^{15}$ A. A. Voityuk, K. Siriwong, and N. Rösch, Angew. Chem., Int. Ed. 43, 624 (2004)

${ }^{16}$ F. L. Gervasio, A. Laio, and M. Parrinello, Phys. Rev. Lett. 94, 158103 (2005).

${ }^{17}$ E. B. Starikov, T. Fujita, H. Watanabe, Y. Sengoku, S. Tanaka, and W. Wenzel, Mol. Simul. 32, 759 (2006).

${ }^{18}$ M. Volobuyev, H. Saint-Martin, and L. Adamowicz, J. Phys. Chem. B 111, 11083 (2007).

${ }^{19}$ H. Yamada, E. B. Starikov, and D. Hennig, Eur. Phys. J. B 59, 185 (2007).

${ }^{20}$ A. A. Voityuk, Chem. Phys. Lett. 439, 162 (2007).

${ }^{21}$ A. A. Voityuk, N. Rösch, M. Bixon, and J. Jortner, J. Phys. Chem. B 104, $9740(2000)$

${ }^{22}$ A. A. Voityuk, J. Jortner, M. Bixon, and N. Rösch, J. Chem. Phys. 114, 5614 (2001)

${ }^{23}$ K. Senthilkumar, F. C. Grozema, C. F. Guerra, F. M. Bickelhaupt, F. D. Lewis, Y. A. Berlin, M. A. Ratner, and L. D. A. Siebbeles, J. Am. Chem. Soc. 127, 14894 (2005).

${ }^{24}$ L. Blancafort and A. A. Voityuk, J. Phys. Chem. A 110, 6426 (2006).

${ }^{25}$ A. A. Voityuk, Chem. Phys. Lett. 427, 177 (2006).

${ }^{26}$ D. L. Beveridge, G. Barreiro, K. S. Byun, D. A. Case, T. E. Cheatham, S. B. Dixit, E. Giudice, F. Lankas, R. Lavery, J. H. Maddocks, R. Osman, E. Seibert, H. Sklenar, G. Stoll, K. M. Thayer, P. Varnai, and M. A. Young, Biophys. J. 87, 3799 (2004).

${ }^{27}$ http://humphry.chem.wesleyan.edu:8080/MDDNA/Download.html

${ }^{28}$ W. D. Cornell, P. Cieplak, C. I. Bayly, I. R. Gould, K. M. Merz, D. M. Ferguson, D. C. Spellmeyer, T. Fox, J. W. Caldwell, and P. A. Kollman, J. Am. Chem. Soc. 117, 5179 (1995).

${ }^{29}$ W. L. Jorgensen, J. Chandrasekhar, J. D. Madura, R. W. Impey, and M. L. Klein, J. Chem. Phys. 79, 926 (1983).

${ }^{30}$ U. Essmann, L. Perera, M. L. Berkowitz, T. Darden, H. Lee, and L. G. Pedersen, J. Chem. Phys. 103, 8577 (1995).

${ }^{31}$ J. E. Ridley and M. C. Zerner, Theor. Chim. Acta 15, 134 (1973).

${ }^{32}$ R. J. Cave and M. D. Newton, J. Chem. Phys. 106, 9213 (1997).

${ }^{33}$ R. J. Cave and M. D. Newton, Chem. Phys. Lett. 249, 15 (1996).

${ }^{34}$ A. A. Voityuk, J. Jortner, M. Bixon, and N. Rösch, Chem. Phys. Lett. 324, 430 (2000).

${ }^{35}$ R. A. Marcus and N. Sutin, Biochim. Biophys. Acta 811, 265 (1985).

${ }^{36}$ M. D. Newton, Chem. Rev. 91, 767 (1991).

${ }^{37}$ A. Troisi, A. Nitzan, and M. A. Ratner, J. Chem. Phys. 119, 5782 (2003).

${ }^{38}$ G. S. M. Tong, I. V. Kurnikov, and D. N. Beratan, J. Phys. Chem. B 106, $2381(2002)$

${ }^{39}$ A. A. Voityuk and N. Rösch, J. Phys. Chem. B 106, 3013 (2002).

${ }^{40}$ I. Saito, T. Nakamura, K. Nakatani, Y. Yoshioka, K. Yamaguchi, and H. Sugiyama, J. Am. Chem. Soc. 120, 12686 (1998). 